\title{
Qualitative Anatomical Characteristics of Compression Wood, Lateral Wood, and Opposite Wood in a Stem of Ginkgo biloba L. 1
}

\author{
Byantara Darsan Purusatama ${ }^{2}$ Yun-Ki $\mathrm{Kim}^{2} \cdot$ Woo Seok Jeon ${ }^{2} \cdot \mathrm{Ju}-\mathrm{Ah} \mathrm{Le \textrm {Le } ^ { 2 }}$ • \\ Ah-Ran $\mathrm{Kim}^{2} \cdot$ Nam-Hun Kim ${ }^{2, \dagger}$
}

\begin{abstract}
This study was conducted to understand and to compare the qualitative aspects of anatomical characteristics in compression wood (CW), lateral wood (LW), and opposite wood (OW) in a stem of Ginkgo biloba. The qualitative analysis was examined by optical microscopy and scanning electron microscopy. CW in Ginkgo biloba disks were dark brown in color, and the OW and LW were light brown in color. CW and OW showed abrupt transitions from earlywood to latewood, while LW showed a gradual transition. Cross sections of CW presented circular tracheids with angular outlines, many intercellular spaces, and varying sizes of lumens. Cross sections of LW and OW showed rectangular tracheids, fewer intercellular spaces, and varying sizes of lumens. In radial sections, CW showed an irregular arrangement of tracheids in earlywood, while LW and OW showed comparatively regular arrangements. Slit-like bordered pits on the tracheid cell wall, piceoid pits in the crossfield, and a few spiral checks were present in CW. LW and OW showed bordered pits with slightly oval-shaped apertures, as well as cuppresoid pits in the crossfields. Rays were primarily uniseriate, with few biseriate rays in the tangential sections of $\mathrm{CW}, \mathrm{LW}$, and $\mathrm{OW}$. The tips of the tracheids were branched in $\mathrm{CW}$ but had a normal appearance in $\mathrm{LW}$ and $\mathrm{OW}$.
\end{abstract}

Keywords: Ginkgo biloba, compression wood, lateral wood, opposite wood, qualitative analysis

\section{INTRODUCTION}

Compression wood $(\mathrm{CW})$ is defined as reaction wood on the lower sides of branches and leaning or crooked stems of coniferous trees and are characterized anatomically by highly lignified tracheids (Timell, 1986; Gardiner et al., 2014). CW functions to shift the leaning stem back to a vertical position by producing compression stress, which pushes the stem back to an upright position (Westing, 1965; Gardiner et al., 2014). It can be recognized by a darkened color on the transverse surface, typically in a wide crescent-shape (Kim et al., 2016). Lateral wood (LW) is defined as an intermediate between opposite wood (OW) and CW, also mentioned as normal wood (Timell, 1986). OW that is light brown in color is directly across from the

${ }^{1}$ Date Received November 27, 2017, Date Accepted December 22, 2017

2 Department of Forest Biomaterials Engineering, College of Forest and Environmental Sciences, Kangwon National University, Chuncheon 24341, Republic of Korea

$\dagger$ Corresponding author: Nam-Hun Kim(e-mail: kimnh@kangwon.ac.kr, ORCID: 0000-0002-4416-0554) 
pith of $\mathrm{CW}$. Anatomical characteristics of $\mathrm{CW}$ are distinctively different than those of OW and LW (Timell, 1978; 1983; 1986; Eom, 1991; 1992; Xu and Eom, 2005). The existence of helical cavities, excessive lignification in the $\mathrm{S}_{2}$ layers, roundness of tracheid cells in cross sections, thicker cell walls, differently shaped pit borders, higher microfibril angles in the $\mathrm{S}_{2}$ layers, absence of $\mathrm{S}_{3}$ layer, and intercellular space were all considered as the anatomical characteristics of $\mathrm{CW}$ (Fujita et al., 1979; Yumoto et al., 1983; Timell, 1986).

As an ancient gymnosperm, many researchers have long been interested in the anatomical characteristics of Ginkgo biloba L. Scott et al. (1962) reported that tracheids in the wood of Ginkgo biloba has conifer-like characteristics, such as bordered pits and uniseriate rays; however, the tracheids were distinctly heterogeneous and had a disordered appearance in the transverse sections. Srivastava (1963) also reported that in young and old stems of Ginkgo contained two types of tracheids: one had wide lumens with thin cell walls and many pits, and another had narrow lumens with thicker cell walls and few or no pits. Idioblasts with druse were frequently found in Ginkgo biloba (Scott et al., 1962; Srivastava, 1963; Timell, 1978; Lee and Eom, 1987; 1988). The star shape of druses could be caused by many crystal components extending to the surface (IAWA committee, 2004).

A few studies had been reported the anatomical characteristics of CW and OW in Ginkgo biloba. Timell (1978) examined the ultrastructure of CW and normal wood in Ginkgo biloba using branch wood as the material. He reported that CW in Ginkgo biloba showed varied tracheids in size, angular outline of cell cross section, helical cavities, and similar ultrastructure to the CW of other gymnosperms. Eom (1991) investigated the anatomical characteristics between $\mathrm{CW}$ and $\mathrm{OW}$ in a branch of Ginkgo biloba and observed distinct differences in both qualitative and quantitative aspects.

In previous studies, the branch wood of Ginkgo biloba was usually used to investigate the anatomical characteristics of its CW (Timell, 1978; Eom, 1991). There was still a lack of information regarding the anatomical characteristics of CW, LW and OW in a stem of Ginkgo biloba. Therefore, this study aimed to understand the qualitative aspects of the anatomical characteristics for $\mathrm{CW}$ in a stem of Ginkgo biloba. These characteristics were then compared to those of LW and OW.

\section{MATERIALS and METHODS}

\subsection{Materials}

A Ginkgo biloba tree of $24 \mathrm{y}$ was obtained from Hongcheon-gun, Gangwon-do, Republic of Korea $\left(37.6970^{\circ} \mathrm{N}, 127.8887^{\circ} \mathrm{E}\right)$. The $\mathrm{CW}$ in a stem of Ginkgo biloba was dark brown in color, while LW and OW were light brown (Fig. 1). The fundamental information of experimental woods is shown in Table 1.

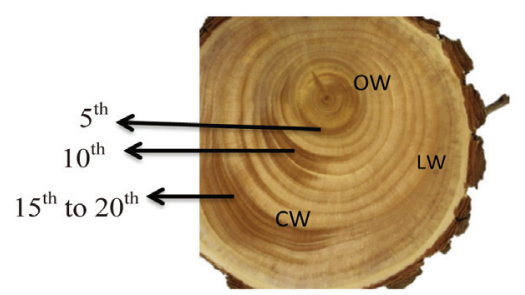

Fig. 1. Compression wood (CW), lateral wood (LW), and opposite wood (OW) in a stem of Ginkgo biloba.

Table 1. The fundamental information of sample tree

\begin{tabular}{ccccccc}
\hline Samples & Age & DBH $(\mathrm{cm})$ & Type & Examined annual ring & Density $\left(\mathrm{g} / \mathrm{cm}^{3}\right)$ \\
\hline \hline \multirow{3}{*}{ Ginkgo biloba } & & & CW & $5^{\text {th }}, 10^{\text {th }}$, and $15^{\text {th }}$ to $20^{\text {th }}$ & 0.50 \\
& 24 & \multirow{2}{*}{15} & LW & $5^{\text {th }}, 10^{\text {th }}$, and $15^{\text {th }}$ to $20^{\text {th }}$ & 0.47 \\
& & OW & $5^{\text {th }}, 10^{\text {th }}$, and $15^{\text {th }}$ to $20^{\text {th }}$ & 0.51 \\
\hline
\end{tabular}


Qualitative Anatomical Characteristics of Compression Wood, Lateral Wood, and Opposite Wood in a Stem of Ginkgo biloba L.

\subsection{Microscopy}

Wood discs were converted to small blocks and softened in a boiling mixture of glycerine and water (50:50). The cross, tangential, and radial sections were cut into pieces with a 15-20 $\mu \mathrm{m}$ thickness using a microtome. All sections were stained with $1 \%$ safranin solution and dehydrated by grade series of alcohol $(50 \%$, $70 \%, 90 \%, 95 \%$, and $99 \%$ ) and xylene. Permanent slides were prepared with Canada balsam. All thin sections were observed under an optical microscope (Eclipse E600, Nikon, Japan) connected to an images analysis system (IMT i-Solution Lite).

The CW, LW, and OW samples were cut to a dimension of $10 \mathrm{~mm}^{3}$, air-dried, coated with gold using a Cressington sputter coater (ULVAC G-50DA, Japan), and observed under a scanning electron microscope (SEM) (JSM-5510, Japan, 15 kV).

\section{RESULTS and DISCUSSION}

\subsection{Characteristics on the Cross Section}

Macroscopically, the $\mathrm{CW}$ in a disc of Ginkgo biloba had a dark brown color, while the LW and OW had a light brown color (Fig. 1). The $\mathrm{CW}$ in Coniferales, Ginkgoales, and Taxales was easily recognized by its color, which was darker than the surrounding tissues, while LW was considered as either normal wood or an intermediate between OW and CW (Timell, 1986).

The transition from earlywood to latewood in a stem of Ginkgo biloba is shown in Fig. 2. The CW and OW had an abrupt transition from earlywood to latewood, while the transition was gradual in LW. The transition was recognizable by the structural differences, usually in wall thickness and radial diameter of tracheid (IAWA Committee 2004). Lee and Eom (1987) reported that Ginkgo biloba exhibited a gradual transition from earlywood to latewood in normal wood stems. The transition from earlywood to latewood could be affected by many factors-one of which was CW (IAWA Committee 2004). Latewood portions in the cross surface have been measured according to Mork's definition under an optical microscope (Denne, 1989). In this study, CW had higher portion of latewood than OW and LW.

Scanning electron micrographs of Ginkgo biloba on transverse sections are shown in Fig. 3. The tracheids in $\mathrm{CW}$ had angular shape, varying lumen size, and several intercellular spaces. The CW in Ginkgo biloba had different anatomical characteristics from $\mathrm{CW}$ in other softwood species (Timell, 1986). Generally, CW showed distinctive anatomical characteristics, such as spiral checks, excessive lignification in the $\mathrm{S}_{2}$ layer,

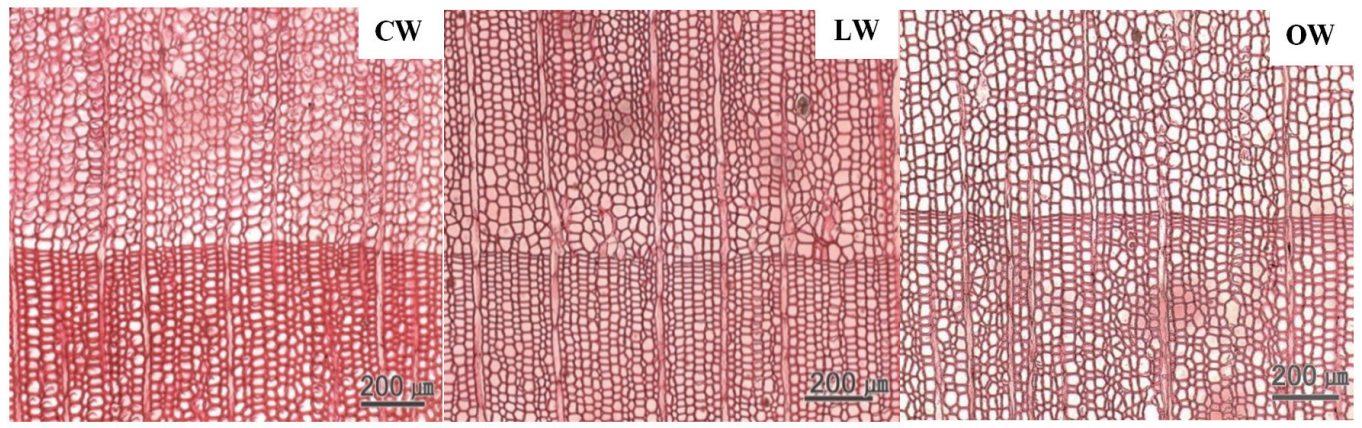

Fig. 2. Light micrographs on the cross section of Ginkgo biloba stem: CW and $\mathrm{OW}$ showed an abrupt transition from earlywood to latewood, while LW showed a gradual transition. 

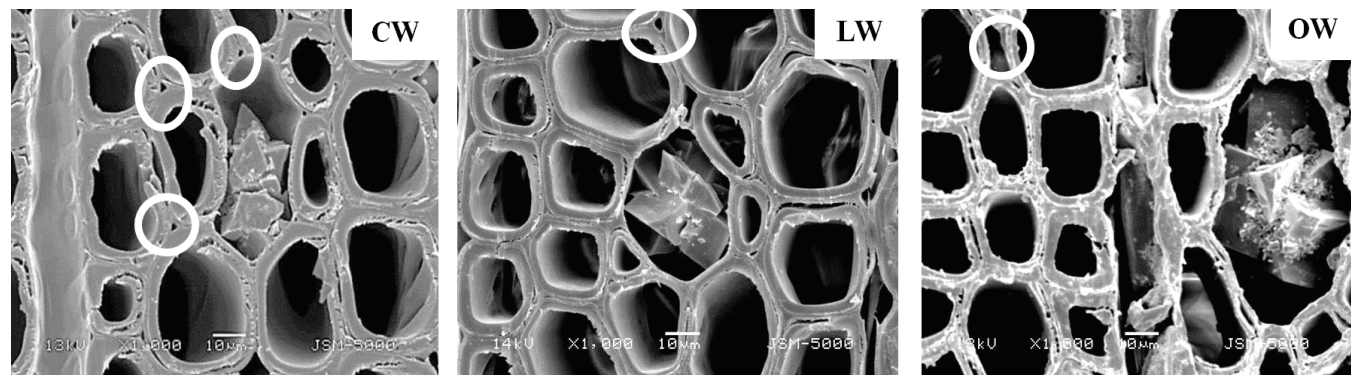

Fig. 3. Scanning electron micrographs on the cross section of Ginkgo biloba stem: CW tracheids were circular with or without an angular outline, many intercellular spaces (white circle), and varied in size; LW and OW tracheids were rectangular, had few intercellular spaces (white circle), and also varied in size. Druses were discovered in CW, LW, and OW.

circular tracheid shape in the cross section, thicker cell walls, changes in the shape of pit borders, higher microfibril angles in the $S_{2}$ layers, absence of $S_{3}$ layers, and intercellular spaces (Timell, 1978; 1983; 1986; Fujita et al., 1979; Yumoto et al., 1983; Donaldson et al., 2004). LW and OW showed rectangular tracheids of varying sizes and fewer intercellular spaces compared to $\mathrm{CW}$ in cross section. Druses, as common characteristics of Ginkgo biloba, were shown in CW, LW, and OW. Idioblasts with druse were found in Ginkgo biloba, usually one idioblast contained one druse (Srivastava, 1963; Lee and Eom, 1988). Druse was defined as a compound crystal of calcium oxalate (Scott et al., 1962; Srivastava, 1963; IAWA committee, 2004). The star shape of druses could be caused by many crystal components extending to the surface (IAWA committee, 2004).

\subsection{Characteristics on the Radial Section}

Scanning electron micrographs of Ginkgo biloba on the radial section are shown in Fig. 4. A radial section of $\mathrm{CW}$ revealed spiral or helical checks in the tracheid cell walls (Fig. 4). It was reported that the spiral or helical checks were present in CW of G. biloba (Onaka, 1949). However, several studies reported that the helical checks were absent in Ginkgo biloba (Timell, 1978; 1983; 1986; Yoshizawa, 1987a). Spiral checks are defined as the slopes of slits or helical lines on the cell wall and could be used to measure the microfibril

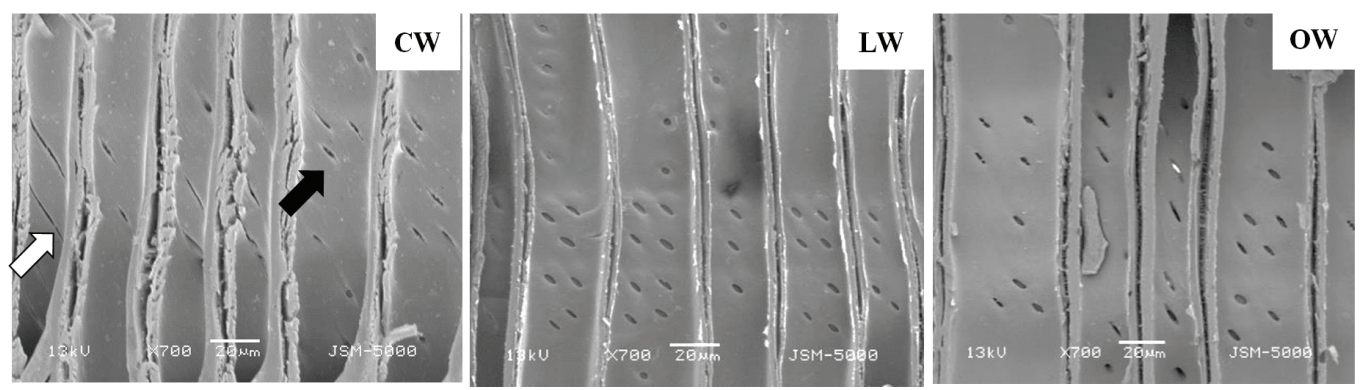

Fig. 4. Scanning electron micrographs on the radial section of Ginkgo biloba stem: Slit-like pits (black arrow), spiral checks (white arrow), and piceoid pits were discovered in the crossfields of CW; LW and OW showed cupressiod pits in the crossfields. 

in a Stem of Ginkgo biloba L.
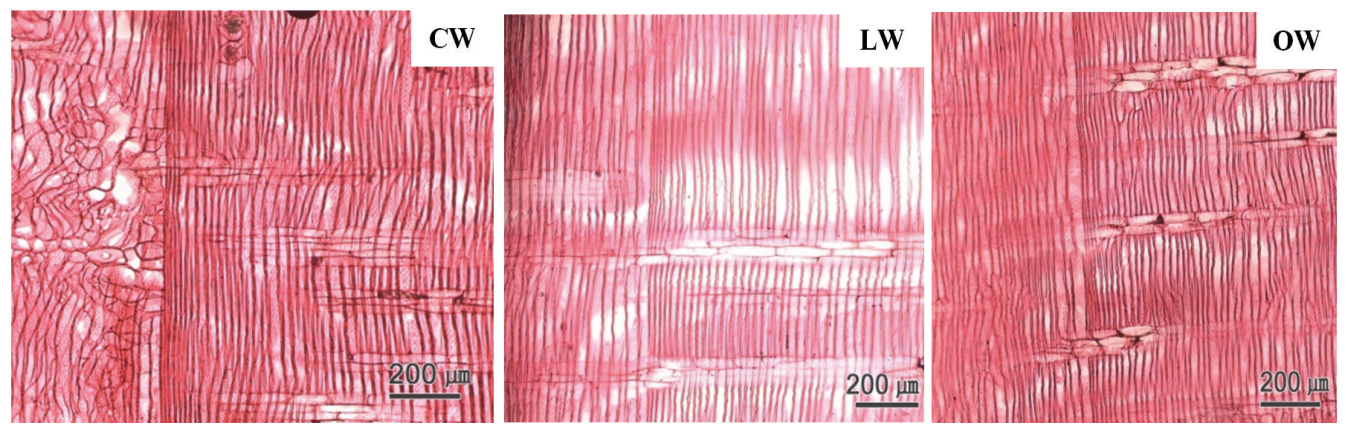

Fig. 5. Light micrographs on the radial section of Ginkgo biloba stem: CW presented a distorted arrangement of tracheids in earlywood; LW and OW showed regular arrangements of tracheids in earlywood.

angle in the $S_{2}$ layer, as the slits of bordered pits were parallel to microfibril orientation occurring in the inner-tracheid walls (Timell, 1986; Hoadley, 1990). LW and OW showed bordered pits with a rounded and slightly oval-shaped pit apertures. The crossfields of CW had slit-like and often extended apertures (known as piceoid pits), while the LW and OW had cupressoid pits in the crossfields. Pit apertures could be affected by the existence of $\mathrm{CW}$, as it could be intergrading between piceoid and cupressoid pits and between cupressoid and taxodioid pits (IAWA committee, 2004). The crossfields of Ginkgo biloba consisted of two to seven cupressoid pits in each field (Lee and Eom, 1987). The CW showed that the arrangement of tracheids was heavily distorted in earlywood (Fig. 5). The occurrence of abnormal or distorted tracheids gradually decreased during the transition from earlywood to latewood in CW (Yoshizawa et al., 1987b). Distorted tracheids in $\mathrm{CW}$ could be an effort to restore normal tracheid function by sliding or forcing the growth of the tracheids (Timell, 1986). A lack of space for growth made some tracheids expand abnormally, and they were displaced by the proximate cells (Yoshizawa et al., 1987b).

\subsection{Characteristics on the Tangential Section}

The types of rays can be investigated through a tangential section as shown in Fig. 6. CW, LW, and OW of Ginkgo biloba primarily contain uniseriate rays,

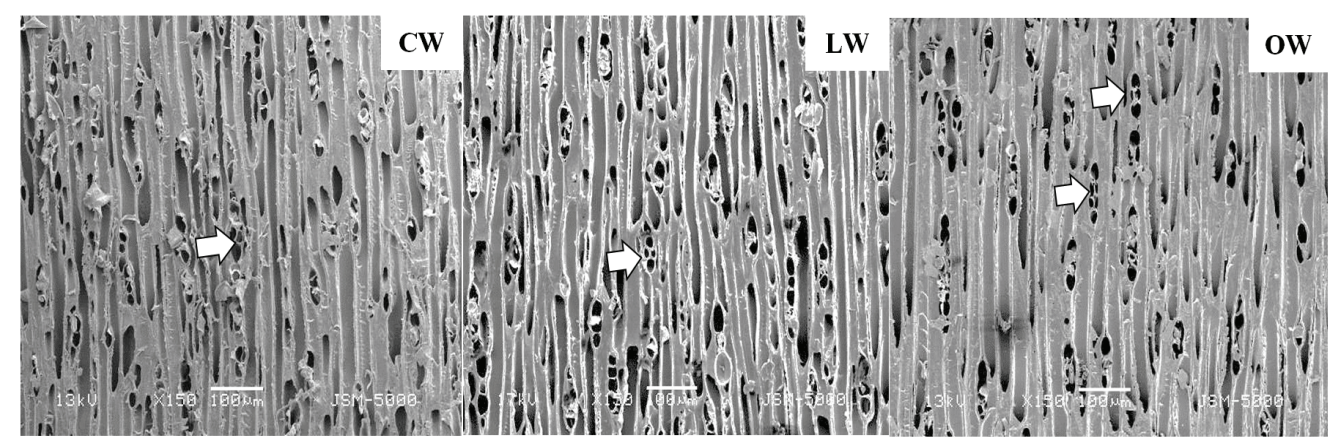

Fig. 6. Scanning electron micrographs on the tangential section of Ginkgo biloba stem: rays are primarily uniseriate with few biseriate rays (white arrows) in $\mathrm{CW}, \mathrm{LW}$, and $\mathrm{OW}$. 


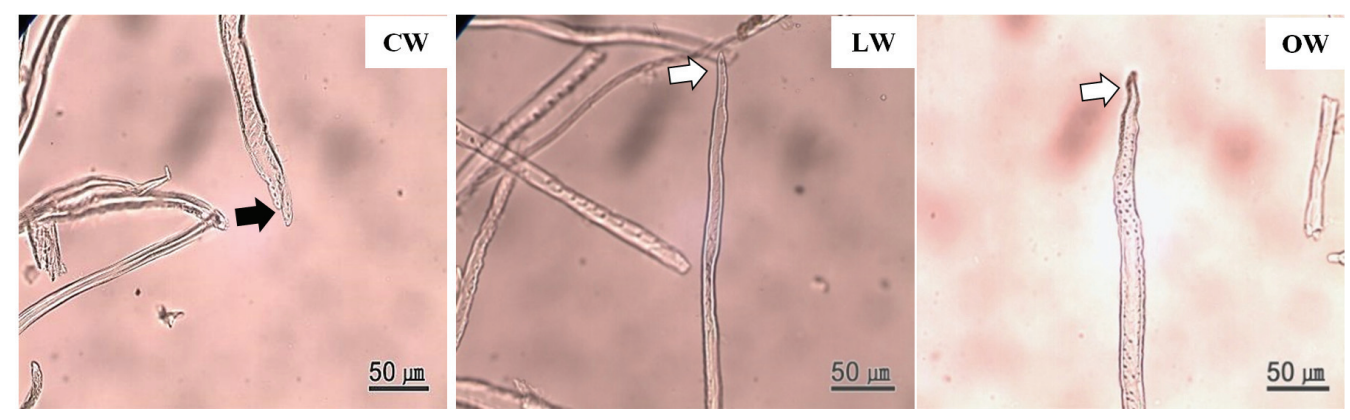

Fig. 7. Light micrographs on the tracheid shape in Ginkgo biloba: CW showed branched tracheid tips (black arrow); LW and OW presented normally shaped tracheid tips (white arrow).

while few biseriate rays were found (Fig. 6). Ginkgo biloba showed almost exclusively uniseriate rays, similar to other conifers (Scott et al., 1962).

\subsection{Characteristics of the Tracheid Tips}

The tips of tracheid in $\mathrm{CW}$ were branched, while those of LW and OW presented a normal appearance (Fig. 7). The bifurcated tracheid tips were common characteristics in CW tracheids (Timell, 1986). The rapidity and quantity of elongation were determined by the interaction between inherent forces among each cell, which influenced the structural change of the tracheid tips in CW (Yoshizawa et al., 1987b).

\section{CONCLUSION}

A cross section of $\mathrm{CW}$ and $\mathrm{OW}$ showed an abrupt transition from earlywood to latewood, while that of LW showed a gradual transition. A cross section of CW revealed circularly shape tracheids with or without angular outlines, many intercellular spaces, and varying lumen sizes. LW and OW showed rectangularly shape tracheids and fewer intercellular spaces compared to the $\mathrm{CW}$, but they also presented varying lumen sizes. In a radial section, $\mathrm{CW}$ showed an irregular arrangement of earlywood tracheids, while LW and OW showed comparatively regular arrangements. CW possessed slit-like bordered pits along the tracheid cell wall, piceoid pits in the crossfield, and few spiral checks. LW and OW had bordered pits with slightly oval-shaped pit apertures and cuppresoid pits in the crossfields. Primarily uniseriate rays and few biseriate rays were observed in a tangential section of $\mathrm{CW}, \mathrm{LW}$, and $\mathrm{OW}$. Tracheids of $\mathrm{CW}$ had bifurcated tips, while tracheids of LW and OW did not.

\section{ACKNOWLEDGMENT}

This study was supported by the 2017 Research Grant from Kangwon National University (No. 52017 0354).

\section{REFERENCES}

Denne, M.P. 1989. Definition of latewood according to Mork (1928). IAWA Journal 10(1): 59-62.

Donaldson, L.A., Grace, J., Downes, G.M. 2004. Within-tree variation in anatomical properties of compression wood in radiata pine. IAWA Journal 25(3): 253-271.

Eom, Y.G. 1991. Anatomical comparison between compression and opposite wood in a branch of Ginkgo biloba L. Journal of the Korean Wood Science and Technology 19(3): 77-85.

Eom, Y.G. 1992. Anatomical comparison between 
Qualitative Anatomical Characteristics of Compression Wood, Lateral Wood, and Opposite Wood in a Stem of Ginkgo biloba L.

compression wood and opposite wood in a straved stem of Abies holophylla Max. Journal of the Korean Wood Science and Technology 12(1): 37-45.

Fujita, M., Saiki, H., Sakamoto, J., Araki, N., Harada, H. 1979. The secondary wall formation of compression wood tracheid. IV: Cell wall structure of transitional tracheids between normal wood and compression wood. Bulletin of the Kyoto University Forests 51: 247-256.

Gardiner, B., Barnett, J., Saranpää, P., Gril, J. eds. 2014. The biology of reaction wood. Springer Science \& Business Media.

Hoadley, R.B. 1990. Identifying wood: accurate results with simple tools. Taunton Press.

IAWA committee 2004. IAWA list of microscopic features for softwood identification. IAWA Journal 25: $1-70$.

Kim, Y.S., Funada, R., Adya, P. 2016. Secondary Xylem Biology: Origins, Functions, and Applications. Academic Press.

Lee, P.W., Eom, Y.G. 1987. Wood identification of the venner species that grow in Korea. II. Wood characteristic and identification by the microscopic features. Journal of the Korean Wood Science and Technology 15(1): 22-55.

Lee, P.W., Eom, Y.G., Chung, Y.J. 1988. The distribution and type of crystals in woods of Ginkgo biloba L. and Abies holophylla Max. Journal of the Korean Wood Science and Technology 16(3): 1-4.

Onaka, F. 1949. Studies on compression and tension wood. Wood Research 24(3):1-88

Timell, T.E. 1978. Ultrastructure of compression wood in Ginkgo biloba L. Wood Science Technology 12:
89-103.

Timell, T.E. 1983. Origin and evolution of compression wood. Holzforschung 37(1): 1-10.

Timell, T.E. 1986. Compression wood in gymnosperms (Vol. 1-3). Springer-Verlag: Berlin, etc.

Scott, R.A., Barghoorn, E.S., Prakash, U. 1962. Wood of Ginkgo in the tertiary of western North America. American Journal of Botany 49(10): 1095-1101.

Srivastava, L.M. 1963. Cambium and vascular derivatives of Ginkgo biloba. Journal of the Arnold Arboretum 44(2): 165-192.

Westing, A.H. 1965. Formation and function of compression wood in gymnosperms. The Botanical Review 31(3): 381-480.

Xu, G.Z., Eom, Y.G. 2005. Anatomical comparison of compression, opposite, and lateral woods in a branch of Pinus parviflora S.et Z. Journal of the Korean Wood Science and Technology 33(1): 38-47.

Yoshizawa, N., Idei, T. 1987a. Some structural and evolutionary aspects of compression wood tracheids. Wood and Fiber Science 19(4): 343-352

Yoshizawa, N., Kiyomiya, M., Idei, T. 1987b. Variations in tracheid length and morphological changes in tracheid tips associated with the development of compression wood. Wood Science and Technology 21(1): 1-10.

Yumoto, M., Ishida, S., Fukazawa, K. 1983. Studies on the formation and structure of the compression wood cells induced by artificial inclination in young trees of Picea glauca: IV. Gradation of the severity of compression wood tracheids. Research Bulletins of the College Experiment Forests Hokkaido University 40(2): 409-454. 